Original Research Paper

\title{
High Deposition Rate of Dual-cathode DC Unbalanced Magnetron Sputtering
}

\author{
${ }^{1}$ Theeranon Chaiyakun, ${ }^{2}$ Wuttichai Phae-Ngam and ${ }^{2}$ Jedsada Prathumsit \\ ${ }^{1}$ Industrial Electrical Technology Program, Faculty of Industrial Technology, \\ Valaya Alongkorn Rajabhat University under the Royal Patronage, Pathumthani 13180, Thailand \\ ${ }^{2}$ Physics Program, Faculty of Science and Technology, Phranakhon Rajabhat University, Bangkok 10220, Thailand
}

\author{
Article history \\ Received: 10-07-2020 \\ Revised: $14-10-2020$ \\ Accepted: 14-10-2020 \\ Corresponding Author: \\ Jedsada Prathumsit \\ Physics Program, Faculty of \\ Science and Technology, \\ Phranakhon Rajabhat \\ University, Bangkok 10220, \\ Thailand \\ Email: jedsada_19@hotmail.com
}

\begin{abstract}
Dual-cathode dc unbalanced magnetron sputtering for the deposition of ternary compound films with a high deposition rate was designed and constructed. It consists of two magnetrons of opposite magnetic polarities. Each magnetron consists of central and outer ring magnets with the residual inductions of 500 and $600 \mathrm{mT}$, respectively. The testing results of the system showed that high plasma volume could be created at a long substrate distance of about $15 \mathrm{~cm}$ from the targets. In addition, by using this sputtering system for coating TiAlN film, the result showed that at a target to substrate distance of $13 \mathrm{~cm}$ the film growth rate was $7.3 \mathrm{~nm} / \mathrm{min}$. It indicates that the sputtering system developed in this study is suitable for large substrate area coating due to the long distance of target to substrate.
\end{abstract}

Keywords: Unbalanced Magnetron, DC Magnetron Sputtering, Dual Cathode

\section{Introduction}

Since the development of the Unbalanced Magnetron (UBM) sputtering cathode in the late 1980s (Window and Savvides, 1986a; 1986b; Savvides and Window, 1986), magnetron sputtering has become the most important technology for the deposition of thin films. Furthermore, several types of magnetron sputtering cathode have been developed continuously from 1980s until recent years (Teer, 1989; Sproul et al., 1990; Kelly and Arnell, 2000; Musil et al., 2005; Rastogi et al., 1978; Swann, 1988; Münz, 1991; Sproul, 1991; Chen et al., 1994; Zheng et al., 1994; Okimura et al., 1995; 1996; Muralidhar et al., 1995; Ai et al., 2000; Ejima and Shimizu, 2001; Pradhan et al., 2002; Svadkovski et al., 2002; Gudmundsson, 2008; Ehiasarian, 2010; Sasaki et al., 2012; Yamada et al., 2014; Britun et al., 2015; Motomura and Tabaru, 2017). Two types of unbalanced magnetron were described by (Window and Savvides, 1986b) as shown in Fig. 1.

For type 1, the residual induction of the central magnet is higher than that of the outer magnet. On the contrary, for type 2 , the residual induction of the central magnet is lower than that of the outer magnet. In the case of type 2, not all the field lines are closed between the central and outer magnets, but some are directed towards the substrate and some secondary electrons are able to follow these field lines. Consequently, the plasma is no longer strongly confined in the target region, but it is also flow out towards the substrate (Kelly and Arnell, 2000).

To increase the plasma density, the closed-field unbalanced magnetron sputtering was proposed. In the closed-field unbalanced magnetron, the magnetic arrays in two adjacent magnetron with opposite magnetic polarities are configured as shown in Fig. 2 (Kelly and Arnell, 2000; Musil et al., 2005).

From Fig. 2, the large plasma volume can be confined at the substrate surface. The large plasma volume with high density and the long distance of the substrate to two magnetrons are required for coating large substrate area with high uniformity and high deposition rate. The above requirements depend on the residual induction of the magnets and the design of magnetron.

For both types of unbalanced magnetron sputtering, most of the magnetron sputtering assemblies have been designed and constructed to achieve high field strength. In recent years, $\mathrm{NdFeB}$ rare-earth permanent magnets have been widely used in magnetron assembly due to high field strength. However, most of the proposed magnetron assemblies, the permanent magnets are placed in the envelope to protect their contact with cooling water. This cause the heat accumulation in the magnets and the decrease of magnetization of the magnet. 


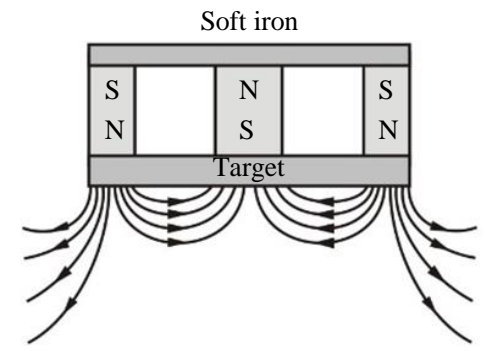

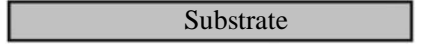

(a)

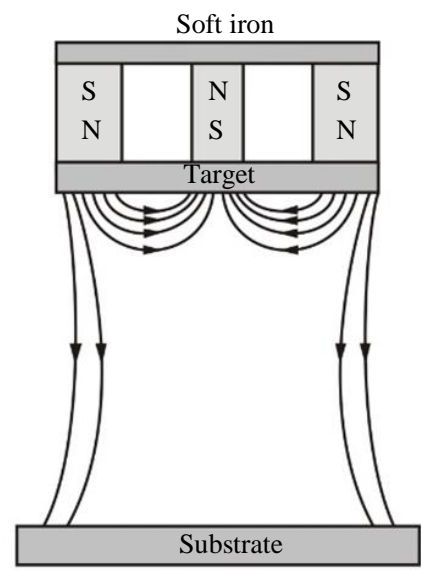

(b)

Fig. 1: Magnetron sputtering cathodes: (a) Type 1 and (b) type 2

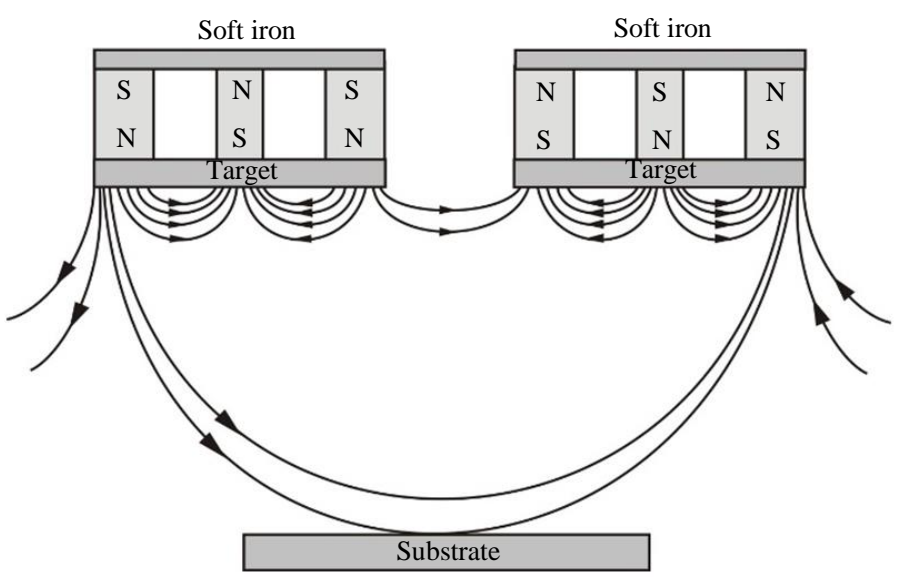

Fig. 2: Closed-field unbalanced magnetron sputtering

As a result, the decrease of magnetic field strength on the target surface. In addition, during the coating, the plasma will be confined only near the target surface and the distance from the target to the substrate to be coated is usually less than $6 \mathrm{~cm}$ (Mei et al., 2005; Wuhrer and Yeung, 2004; Irudayaraj et al., 2007).

By those conventional sputtering systems, only the substrates with a small area can be coated with good uniformity.

In this study, the dual-cathode dc unbalanced magnetron sputtering for the deposition of ternary compound films with a high deposition rate and a large substrate area was designed and constructed. To test the developed system, a typical coating of TiAlN film was carried out and presented. The TiAlN film was selected because it is a ternary nitride film which has been attracting more attention due to high hardness, high temperature oxidation resistance and low friction coefficient (Arulkirubakaran and Senthilkumar, 2017; Kong and $\mathrm{Fu}, 2015)$.

\section{Experimental Details}

Figure 3 shows a schematic diagram of the cross section of the planar unbalanced magnetron source proposed in this study. The cylindrical body of the magnetron sputtering assembly could be divided into 3 main parts: (1) Cathode part (yellow color), (2) anode part (green) and (3) insulator (blue) to isolate between cathode and anode.

The cathode part consists of cathode assembly made up of stainless-steel no. 304 which is a nonferromagnetic material. It has two holes for water inlet and water outlet and the cavity inside for cooling the magnets and target. Two permanent magnets were attracted tightly, due to magnetic force, with a $10 \mathrm{~mm}$ thick iron steel plate (i.e., ferromagnetic material) which was mounted with cathode assembly by screws. The outer magnet is a ring magnet with the inner and outer diameters of 53 and 85 $\mathrm{mm}$, respectively. The central magnet has a cylindrical shape with a diameter of $15 \mathrm{~mm}$ and a thickness of 15 $\mathrm{mm}$. The residual induction of the central and ring magnets were 500 and $600 \mathrm{mT}$, respectively. 


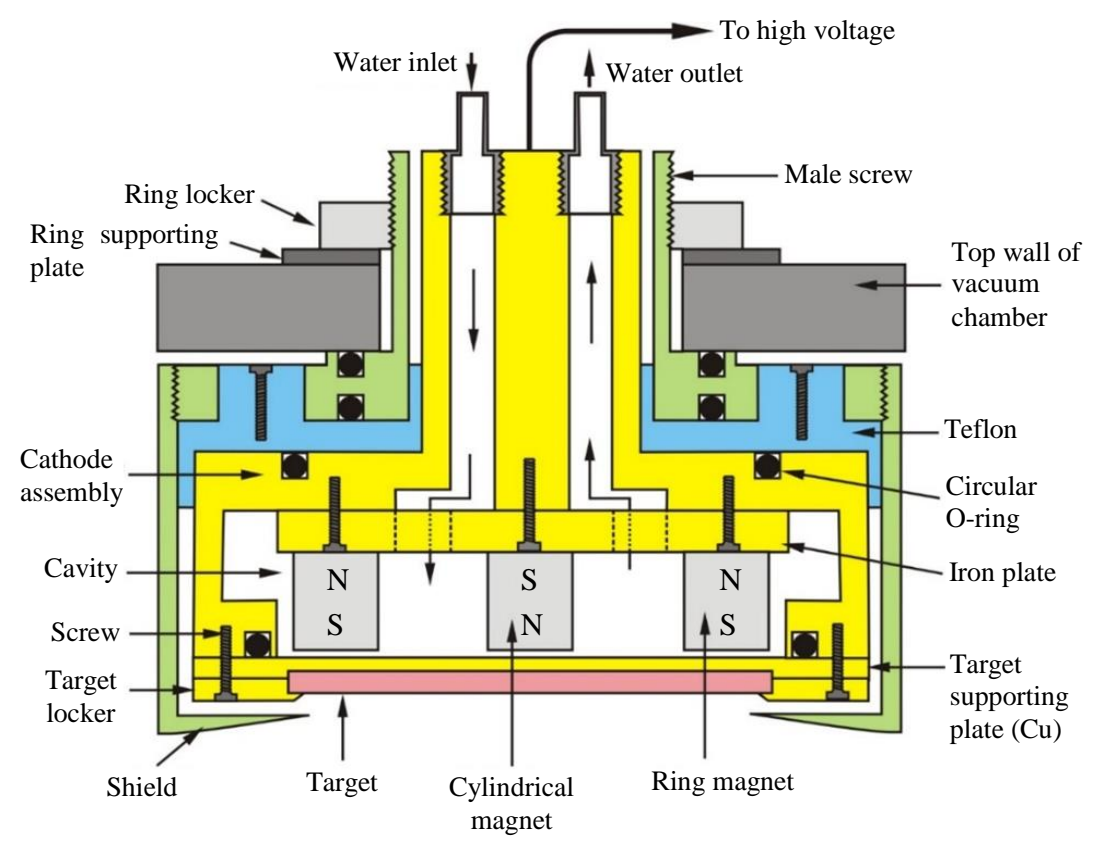

Fig. 3: Cross section of planar unbalanced magnetron sputtering assembly

The circular copper plate with a thickness of $2 \mathrm{~mm}$ was used as the target supporter and tighten with the target locker by screws. The maximum diameter of the target that can be used with this cathode assembly is 3 inches. All parts mentioned above and the target behaves as cathode and will be supplied by high voltage at the top of cathode assembly.

The anode part is the outer part of magnetron sputtering assembly. It consists of stainless-steel shield with a cylindrical shape and held with male nut of stainless-steel plate which isolated from cathode assembly by Teflon plate.

Then, the magnetron sputtering assembly was inserted through the drilled hole on the top wall of the vacuum chamber. It was tightened with the wall by the stainless-steel ring locker and ring supporting plate. After the magnetron assembly was installed through the hole on the top wall of the vacuum chamber, the wall was contacted with anode part, hence the wall of the vacuum chamber also behaves as anode.

In this study, two sets of the magnetron sputtering assembly with the same dimension and characteristics but opposite magnetic polarities were designed and constructed. Both sets were installed in the vacuum chamber to be used as the dual-cathode dc unbalanced magnetron sputtering system.

Figure 4 shows the schematic diagram of the closedfield dual-cathode dc unbalanced magnetron sputtering system designed and constructed in our laboratory. A typical example for thin film coating using dual-cathode dc magnetron sputtering system is TiAlN. Hence, the target of one magnetron sputtering assembly is metallic $\mathrm{Ti}$ and the other one is metallic $\mathrm{Al}$.

Furthermore, two shutters were installed to be used as open-close window for each target. Two separated dc power supplies, each one with a maximum power of 600 $\mathrm{W}$ were developed and used to supply the dc current for each target independently.

The vacuum chamber has a distance $\left(\mathrm{d}_{\mathrm{t}-\mathrm{s}}\right)$ from the target to the substrate holder of about $23 \mathrm{~cm}$. However, the height of substrate holder can be adjusted and it can be rotated by a motor with a maximum angular velocity of $100 \mathrm{rpm}$. The vacuum pump system consists of a rotary pump and a diffusion pump. The base pressure of the vacuum chamber was $1.0 \times 10^{-5} \mathrm{mbar}$.

The metallic $\mathrm{Ti}$ disc and metallic $\mathrm{Al}$ disc with a purity of 99.97 and $99.99 \%$ (Kurt J. Lesker), respectively were used as sputtering targets. The Ar gas $(99.999 \%$, TIG) and $\mathrm{N}_{2}$ gas $(99.99 \%$, TIG) were used as sputtering gas and reactive gas, respectively.

A typical deposition of TiAlN thin film on $\mathrm{Si}(100)$ wafer was carried out. The distance from the center between two targets to the substrate was $13 \mathrm{~cm}$, that is, it was placed in the plasma volume. The conditions used for the deposition of TiAlN thin film are presented in Table 1.

The crystalline structure of the TiAlN film was characterized by X-Ray Diffraction (XRD: Rigaku, Rint 2000) using $\mathrm{Cu} \mathrm{K} \alpha$ radiation $(\lambda=0.1542 \mathrm{~nm})$. The XRD patterns were recorded at grazing incidence angle of $3^{\circ}$ from $10^{\circ}-80^{\circ}$ of a $2 \theta$ range with a scanning speed of $2 \% \mathrm{~min}$. 


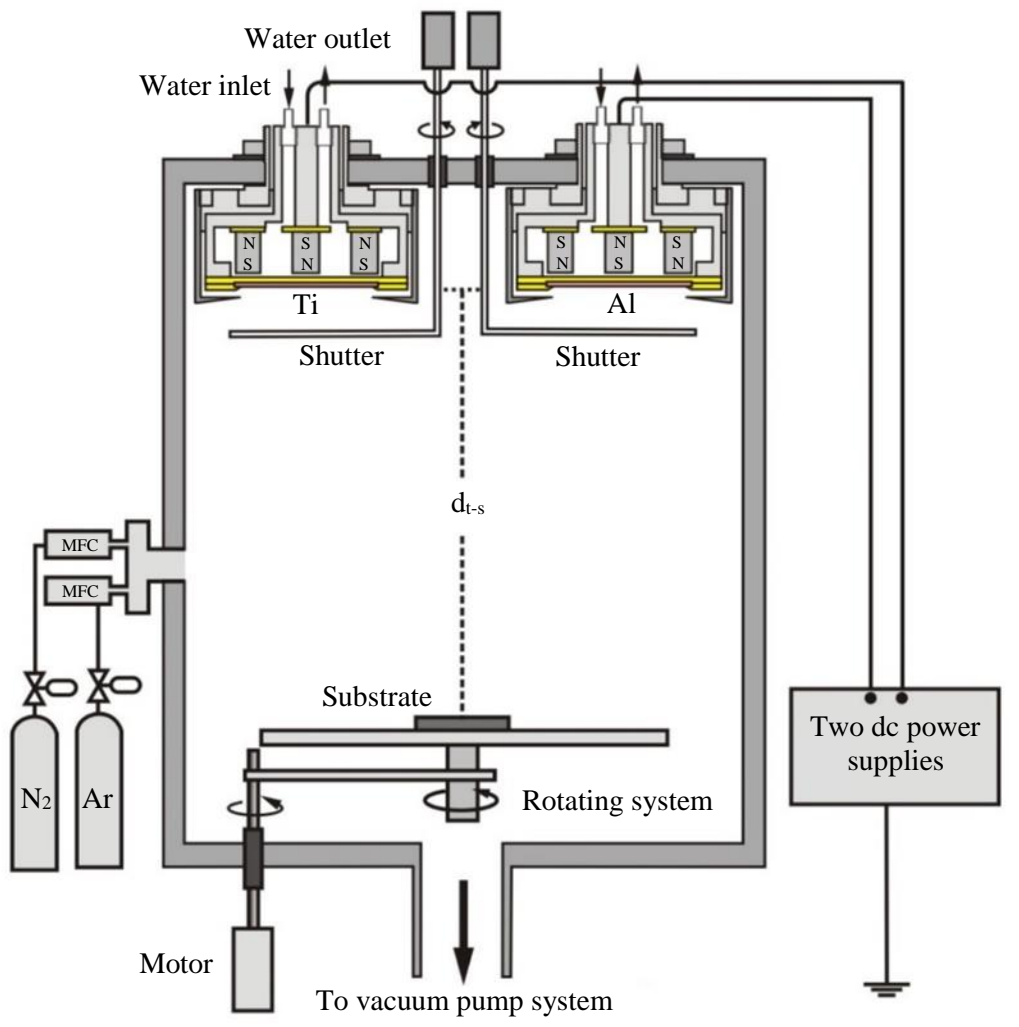

Fig. 4: Schematic diagram of the closed-field dual-cathode dc unbalanced magnetron sputtering

Table 1: Deposition conditions for the deposition of TiAlN film

\begin{tabular}{ll}
\hline Parameters & Details \\
\hline Base pressure (mbar) & $1.0 \times 10^{-5}$ \\
Working pressure (mbar) & $2.0 \times 10^{-3}$ \\
Ar flow rate (sccm) & 20 \\
$\mathrm{~N}_{2}$ flow rate (sccm) & 2 \\
Ti sputtering current, $\mathrm{I}_{\mathrm{Ti}}(\mathrm{mA})$ & 1,000 \\
$\mathrm{Al}$ sputtering current, $\mathrm{I}_{\mathrm{Al}}(\mathrm{mA})$ & 250 \\
Deposition time (min) & 30 \\
\hline
\end{tabular}

The cross-sectional morphology of the TiAlN film was investigated by Field Emission Scanning Electron Microscopy (FE-SEM: Hitachi, S-4700) with the operating voltage of $5.0 \mathrm{kV}$.

The surface morphology of the TiAlN film was investigated by atomic force microscopy (AFM: Veeco, Nanoscope IV) which operated in the tapping mode on a scanning area of $1 \times 1 \mu \mathrm{m}^{2}$.

\section{Results and Discussion}

Figure 5 shows the magnetic field lines of the closedfield dual-cathode unbalanced magnetron sputtering and the magnetic field strength along the magnetic field lines at different dt-s distances from the center between two cathodes and at different positions from the target as simulated by Vizimag program (Version. 3.18.).
As mentioned earlier that the residual induction of the ring magnet and central magnet are 500 and $600 \mathrm{mT}$, respectively. In this design, the magnetic field strength at the center of target surface is $232 \mathrm{mT}$ and at the edge of target surface is about $210 \mathrm{mT}$. To demonstrate the effect of magnetic field on the Ar gas plasma occurred during the sputtering, the vacuum chamber was evacuated to the base pressure of $1.0 \times 10^{-5}$ mbar. Then, the Ar gas was flowed into the chamber with a flow rate of $20 \mathrm{sccm}$ until a pressure was about $2.0 \times 10^{-3}$ mbar and both $\mathrm{Ti}$ and $\mathrm{Al}$ targets were supplied with the same sputtering current $\left(\mathrm{I}_{\mathrm{Ti}}=\mathrm{I}_{\mathrm{Al}}\right)$ at 400, 600, 800 and 1,000 mA. Figure 6 shows the photos of Ar gas plasma at a pressure of $2.0 \times 10^{-3}$ mbar and different sputtering currents.

The lowest positions of the plasma in Fig. 6 were 14, 14, 15.5 and $15.5 \mathrm{~cm}$ from the center between two cathodes for sputtering currents of 400, 600, 800 and 1,000 mA, respectively. The above values were obtained from Fig. 7 which are the black and white photos of Fig. 6 .

It is seen that the intense plasma with a long distance from the targets was observed. This confirms that the closed-field dual-magnetron sputtering assembly developed in this study gives a high magnetic field strength inside the vacuum chamber which results in the glowing discharge with a large plasma volume. Furthermore, the plasma could occur on the substrate surface at a long distance from the targets. 


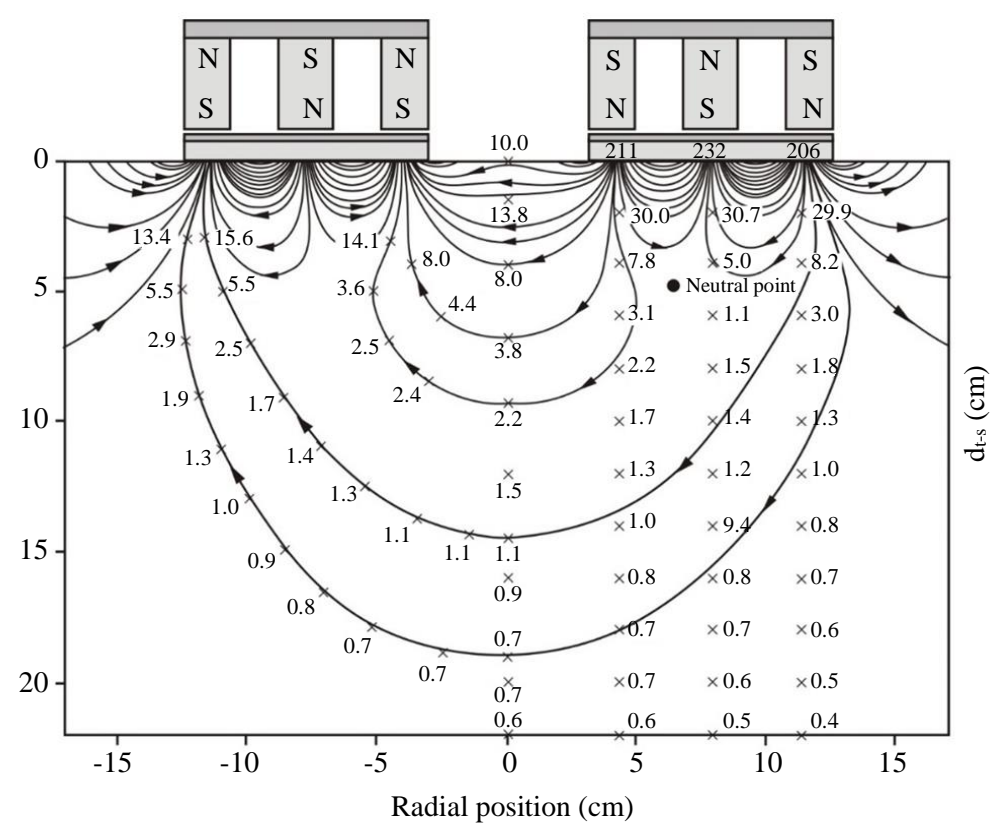

Fig. 5: Magnetic field lines of the closed-field dual-cathode unbalanced magnetron sputtering
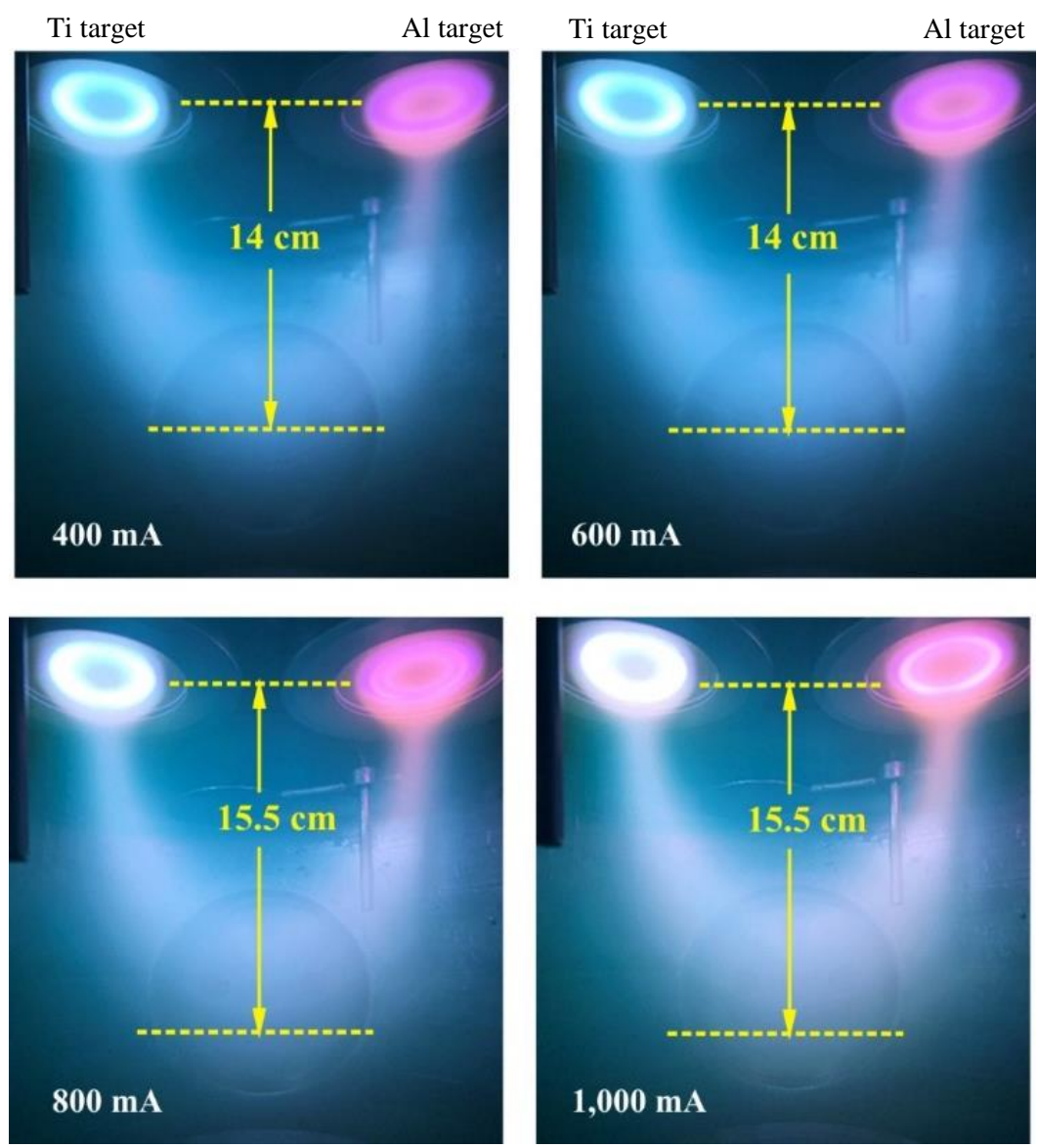

Fig. 6: Photos showing Ar gas plasma at a pressure of $2.0 \times 10^{-3}$ mbar and different sputtering currents $\left(\mathrm{I}_{T i}=\mathrm{I}_{\mathrm{Al}}\right)$ of $400,600,800$ and $1,000 \mathrm{~mA}$ 

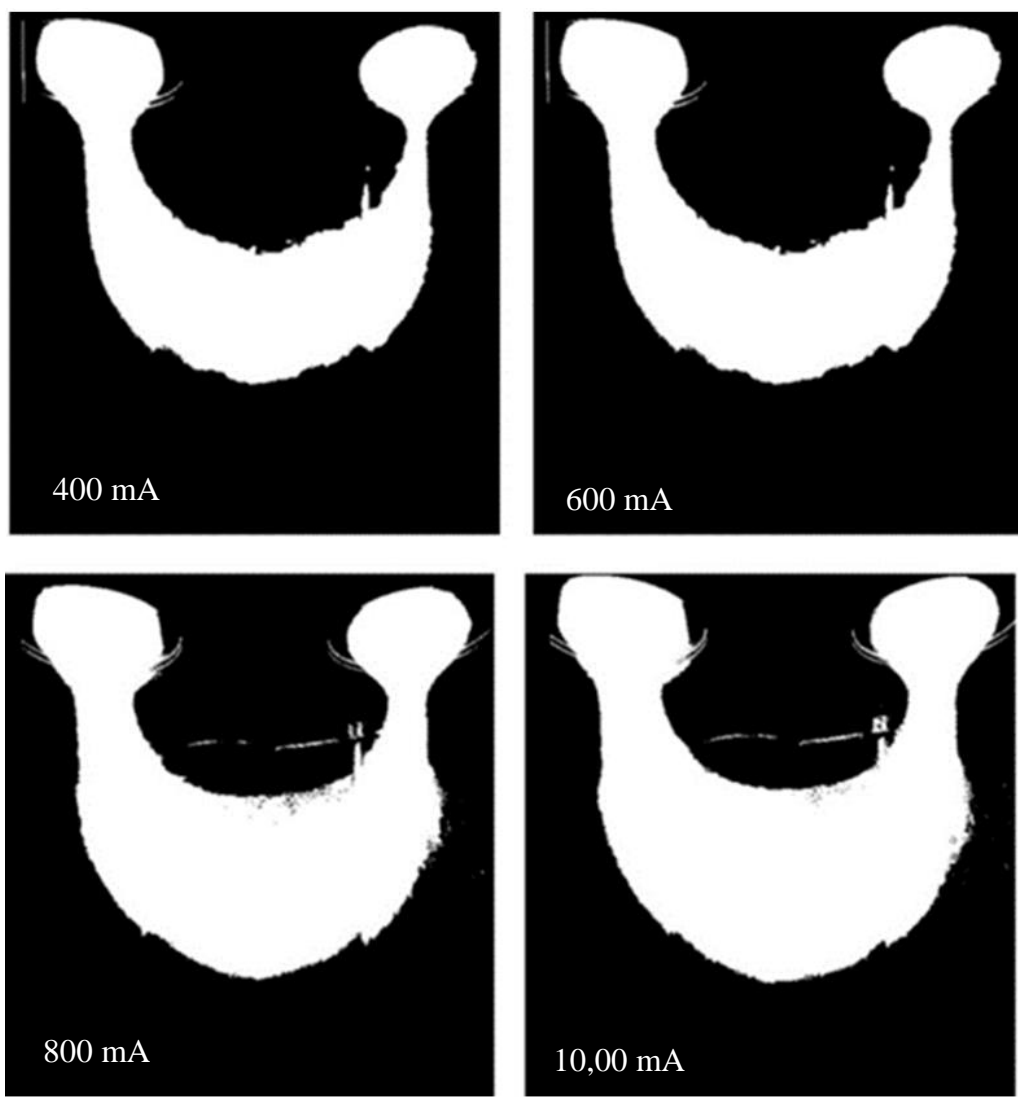

Fig. 7: Black and white (50\%) photos of Fig. 6

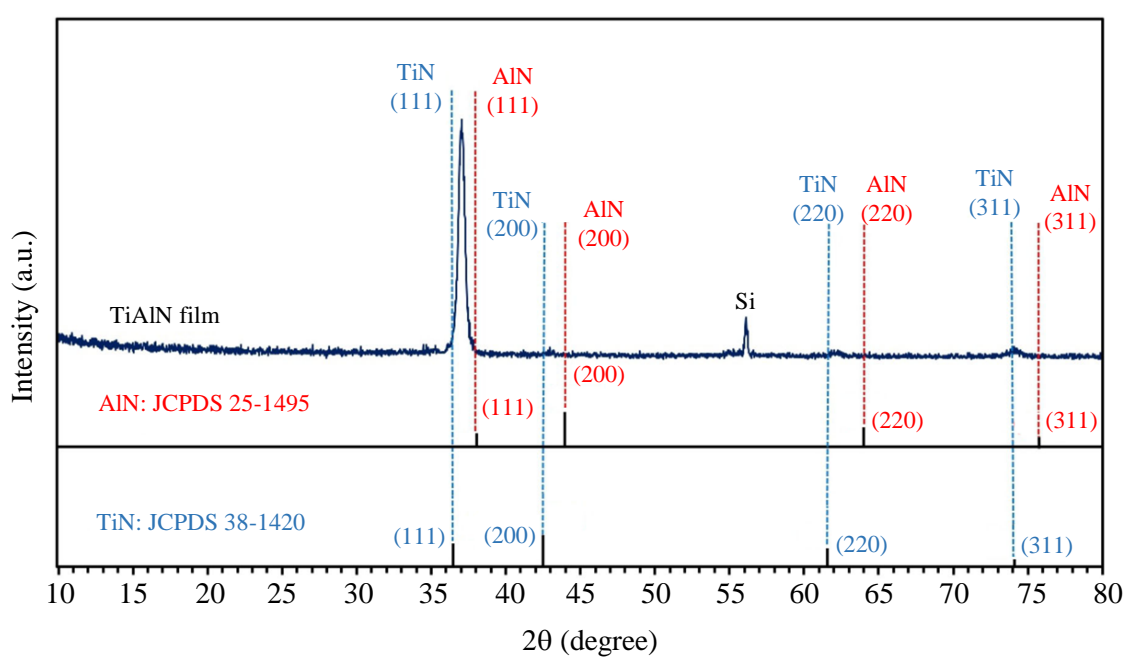

Fig. 8: XRD patterns of the TiAlN film

For the deposition of TiAlN thin film on $\mathrm{Si}(100)$ wafer with the deposition conditions as given in Table 1, the obtained TiAlN film was characterized by XRD, FESEM and AFM, respectively.

Figure 8 shows the XRD patterns of the TiAlN film deposited on $\mathrm{Si}(100)$ wafer. The JCPDS data of the fcc
B1 structure TiN (\#38-1420) and AlN (\#25-1495) were used as references. It was observed that the diffraction patterns of TiAlN film were consistence with those of TiN and AlN. The diffraction peaks were located in between the peaks of TiN and AIN. However, the peaks tend to shift to TiN due to $\mathrm{I}_{\mathrm{Ti}}$ is higher than $\mathrm{I}_{\mathrm{Al}}$. 


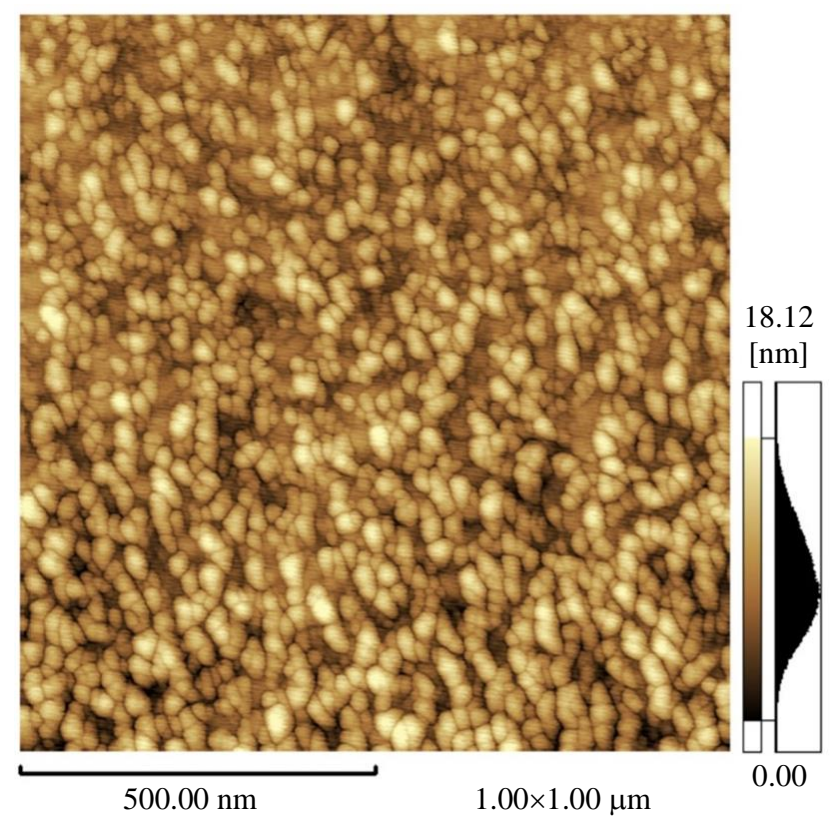

Fig. 9: FE-SEM image of the TiAlN film

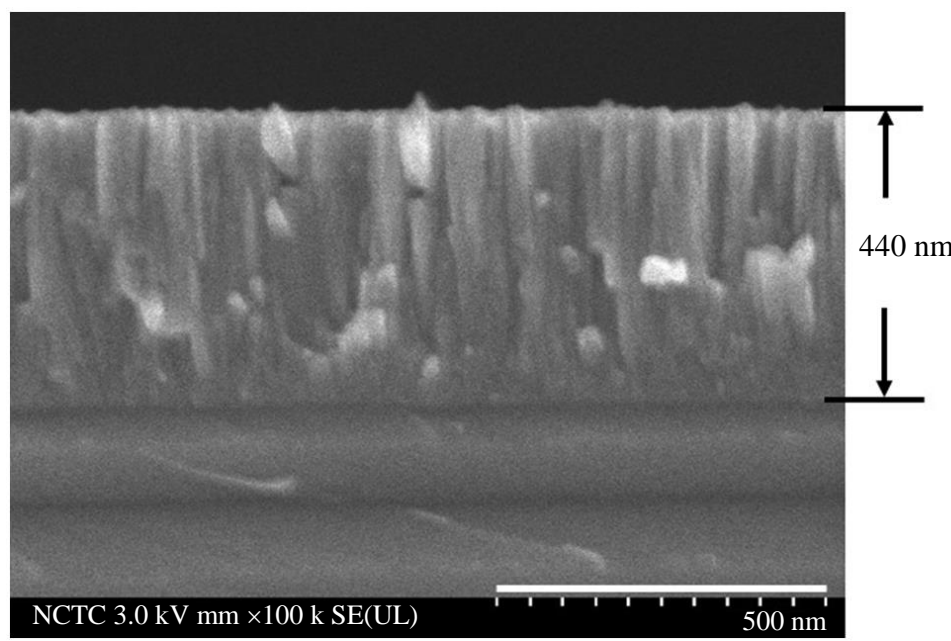

Fig. 10: AFM image of the TiAlN film surface

Figure 9 shows the cross-sectional SEM image of the TiAlN film. The result revealed that the film showed columnar structure with a thickness of $440 \mathrm{~nm}$. The deposition rate, as calculated by the thickness and the deposition time, was found to be $7.3 \mathrm{~nm} / \mathrm{min}$.

It is seen that the film growth by the dual-cathode $\mathrm{dc}$ unbalance magnetron sputtering system developed in this study gives higher growth rate than those of dc magnetron sputterings as previously reported in the literatures in which the TiAlN films were prepared at the target to substrate distance of less than $6 \mathrm{~cm}$ (Mei et al., 2005; Wuhrer and Yeung, 2004; Irudayaraj et al., 2007).

Figure 10 shows the AFM image of the TiAlN film surface. It was found that the average grain size and the root mean square roughness $\left(\mathrm{R}_{\mathrm{rms}}\right)$ of the film were 18 and $2.7 \mathrm{~nm}$, respectively.

\section{Conclusion}

Two sets of magnetron sputtering with the same dimension and characteristic but opposite magnetic polarities were designed and constructed. Both magnetrons were installed in a vacuum chamber as a closed-field unbalanced magnetron sputtering. Two dc power supplies, each one with a maximum power of 600 W were developed and supplied to two magnetrons independently. By using the developed sputtering system for coating TiAlN film, the results show that at a target 
to substrate distance of $13 \mathrm{~cm}$ the film growth rate was $7.3 \mathrm{~nm} / \mathrm{min}$. It can be concluded that this sputtering system is suitable for large substrate area coating with high uniformity.

\section{Acknowledgment}

This research was supported by Physics Program, Faculty of Science and Technology, Phranakhon Rajabhat University and Valaya Alongkorn Rajabhat University under the Royal Patronage.

\section{Funding}

This work was financially supported by Physics Program, Phranakhon Rajabhat University, Bangkok, Thailand and Industrial Electrical Technology Program, Valaya Alongkorn Rajabhat University under the Royal Patronage, Pathumthani, Thailand.

\section{Authors Contributions}

Theeranon Chaiyakun: Provided all the equipments used in the experimental setup.

Wuttichai Phae-Ngam: Read and approved the manuscript

Jedsada Prathumsit: Setup and carried out the experiment, collected all the measurement data and prepared the original manuscript.

\section{Compliance with Ethical Standards}

This article is original and contains unpublished material. It is confirmed that all of the authors have read and approved the manuscript and there are no ethical issues involved.

\section{Conflicts of Interest}

There are no conflicts of interest on this article for the authors.

\section{Ethical Approval}

This article does not contain any work with human participants or animals.

\section{References}

Ai, R., Wasa, K., \& Ichikawa, Y. (2000). Magnetron sputtering cathode with confined magnetic flux. Vacuum, 59(2-3), 466-471.

Arulkirubakaran, D., \& Senthilkumar, V. (2017). Performance of TiN and TiAlN coated microgrooved tools during machining of Ti-6Al-4V alloy. International Journal of Refractory Metals and Hard Materials, 62, 47-57.
Britun, N., Palmucci, M., Konstantinidis, S., \& Snyders, R. (2015). Particle visualization in high-power impulse magnetron sputtering. II. Absolute density dynamics. Journal of Applied Physics, 117(16), 163303.

Chen, X. H., Fan, Q. H., Chen, H. Y., \& Zhang, Y. (1994). Symmetrical magnet magnetron sputtering method for improving target utilization. Review of scientific instruments, 65(8), 2693-2695.

Ejima, S., \& Shimizu, Y. (2001). Magnetic dome configuration for magnetron sputtering. Review of Scientific Instruments, 72(5), 2374-2379.

Ehiasarian, A. P. (2010). High-power impulse magnetron sputtering and its applications. Pure and applied chemistry, 82(6), 1247-1258.

Gudmundsson, J. T. (2008, March). Ionized physical vapor deposition (IPVD): magnetron sputtering discharges. In Journal of Physics: Conference Series (Vol. 100, No. 8, p. 082002).

Irudayaraj, A. A., Kuppusami, P., Thirumurugesan, R., Mohandas, E., Kalainathan, S., \& Raghunathan, V. S. (2007). Influence of nitrogen flow rate on growth of TiAlN films prepared by DC magnetron sputtering. Surface engineering, 23(1), 7-11.

Kelly, P. J., \& Arnell, R. D. (2000). Magnetron sputtering: a review of recent developments and applications. Vacuum, 56(3), 159-172.

Kong, D., \& Fu, G. (2015). Nanoindentation analysis of TiN, TiAlN and TiAlSiN coatings prepared by cathode ion plating. Science China Technological Sciences, 58(8), 1360-1368.

Musil, J., Baroch, P., Vlček, J., Nam, K. H., \& Han, J. G. (2005). Reactive magnetron sputtering of thin films: present status and trends. Thin solid films, 475(1-2), 208-218.

Münz, W. D. (1991). The unbalanced magnetron: current status of development. Surface and Coatings Technology, 48(1), 81-94.

Muralidhar, G. K., Musil, J., \& Kadlec, S. (1995). An unbalanced magnetron sputtering device for low and medium pressures. Review of scientific instruments, 66(10), 4961-4966.

Motomura, T., \& Tabaru, T. (2017). Magnetron sputtering cathode for low power density operation. AIP Advances, 7(12), 125225.

Mei, F., Shao, N., Wei, L., \& Li, G. (2005). Effect of N2 partial pressure on the microstructure and mechanical properties of reactively sputtered $(\mathrm{Ti}, \mathrm{Al}) \mathrm{N}$ coatings. Materials Letters, 59(17), 2210-2213.

Okimura, K., Shibata, A., Maeda, N., Tachibana, K., Noguchi, Y., \& Tsuchida, K. (1995). Preparation of rutile $\mathrm{TiO}_{2}$ films by $\mathrm{RF}$ magnetron sputtering. Japanese journal of applied physics, 34(9R), 4950. 
Okimura, K., Maeda, N., \& Shibata, A. (1996). Characteristics of rutile $\mathrm{TiO} 2$ films prepared by $\mathrm{rf}$ magnetron sputtering at a low temperature. Thin Solid Films, 281, 427-430.

Pradhan, A. A., Shah, S. I., \& Unruh, K. M. (2002). Reactive sputter deposition of alumina thin films using a hollow cathode sputtering source. Review of scientific instruments, 73(11), 3841-3845.

Rastogi, R. S., Vankar, V. D., \& Chopra, K. L. (1987). Simple planar magnetron sputtering source. Review of scientific instruments, 58(8), 1505-1506.

Savvides, N., \& Window, B. (1986). Unbalanced magnetron ion-assisted deposition and property modification of thin films. Journal of Vacuum Science \& Technology A: Vacuum, Surfaces and Films, 4(3), 504-508.

Sproul, W. D., Rudnik, P. J., Graham, M. E., \& Rohde, S. L. (1990). High rate reactive sputtering in an opposed cathode closed-field unbalanced magnetron sputtering system. Surface and Coatings Technology, 43, 270-278.

Sproul, W. D. (1991). Multi-cathode unbalanced magnetron sputtering systems. Surface and Coatings Technology, 49(1-3), 284-289.

Swann, S. (1988). Magnetron sputtering. Physics in technology, 19(2), 67.

Svadkovski, I. V., Golosov, D. A., \& Zavatskiy, S. M. (2002). Characterisation parameters for unbalanced magnetron sputtering systems. Vacuum, 68(4), 283-290.
Sasaki, D., Ieki, S., Kasuya, T., \& Wada, M. (2012). Hollow target magnetron-sputter-type solid material ion source. Review of Scientific Instruments, 83(2), $02 \mathrm{~B} 715$.

Teer, D. G. (1989). A magnetron sputter ion-plating system. Surface and Coatings Technology, 39, 565-572.

Window, B., \& Savvides, N. (1986a). Charged particle fluxes from planar magnetron sputtering sources. Journal of Vacuum Science \& Technology A: Vacuum, Surfaces and Films, 4(2), 196-202.

Window, B., \& Savvides, N. (1986b). Unbalanced dc magnetrons as sources of high ion fluxes. Journal of Vacuum Science \& Technology A: Vacuum, Surfaces and Films, 4(3), 453-456.

Wuhrer, R., \& Yeung, W. Y. (2004). A comparative study of magnetron co-sputtered nanocrystalline titanium aluminium and chromium aluminium nitride coatings. Scripta Materialia, 50(12), 1461-1466.

Yamada, N., Kasuya, T., Tsubouchi, N., \& Wada, M. (2014). Hollow metal target magnetron sputter type radio frequency ion source. Review of Scientific Instruments, 85(2), $02 \mathrm{C} 106$.

Zheng, S., Sun, G., Wang, P., \& Liao, X. (1994). A small unbalanced magnetron sputtering source with multipole magnetic field anode. Review of scientific instruments, 65(4), 1331-1333. 